\title{
Ethnic disparities in the oral health of three- to four-year-old children in East London
}

\author{
W. Marcenes, ${ }^{* 1}$ V. E. Muirhead, ${ }_{1}$ S. Murray, ${ }_{1}{ }^{2}$ P. Redshaw, ${ }_{1}{ }^{2}$ \\ U. Bennett ${ }^{2}$ and D. Wright ${ }^{1,2}$
}
IN BRIEF
- Findings will have profound implications for the commissioning of dental services and oral health promotion.
- Demonstrates a disparity between the oral health of Whites, Blacks and Asians.
- Reports that preschool children a White Eastern European background are at significantly higher risk of developing caries and having untreated caries than children from any other ethnic group.

Aim To report ethnic differences related to caries experience among three- to four-year-old children living in three of the most deprived boroughs in the UK in Inner North East London: Tower Hamlets, Hackney and Newham. Methods This cross-sectional survey used a cluster sampling study design following the British Association for the Study of Community Dentistry protocol. Twenty nurseries from each borough were randomly selected and all three- to four-year-old children in selected nurseries were invited to participate $(n=2,434)$. Calibrated dentists examined children. Demographic information was obtained from schools. Results One thousand, two hundred and eighty-five children were examined in 60 nurseries (response rate $=52.8 \%)$. Twenty-four percent of three- to four-year-old children had caries experience (mean $\mathrm{dmft}=0.92)$. Few children (2.1\%) had filled teeth. Children living in Hackney had significantly lower dmft scores (mean $=0.63)$ than children living in Newham (mean $=1.06)$ and Tower Hamlets (mean $=1.06)$. White European (mean = 1.91), Bangladeshi $($ mean $=1.05)$ and Pakistani $($ mean $=1.11)$ children had a significantly higher number of untreated carious teeth than White British children (mean = 0.56). Conclusion Preschool children from a White Eastern European, Bangladeshi and Pakistani background are likely to experience significantly poorer oral health than their White British counterparts. These findings have profound implications for commissioning dental services and oral health promotion.

\section{INTRODUCTION}

Dental caries in children is still a public health problem in the UK. It negatively affects children's oral health-related quality of life causing disturbances such as pain, impaired speaking and eating and sleeping disruptions. ${ }^{1,2}$ Dental pain caused by untreated dental caries is the most common presenting complaint among children seeking emergency dental visits and hospitalisation. ${ }^{3}$ The consequences of untreated dental caries may also be long-lasting restricting body weight and children's growth. ${ }^{4}$ The wider impacts of child dental caries include school absences and family impacts such as work disruptions when parents take their children to the dentist. ${ }^{5,6}$ Thus dental caries can often present a significant societal burden

\footnotetext{
Institute of Dentistry, Barts and The London School of Medicine and Dentistry, Queen Mary University of London; ${ }^{2}$ NHS East London and the City

${ }^{*}$ Correspondence to: Professor Wagner Marcenes

Email:w.marcenes@qmul.ac.uk;

Tel: +44 (0) 2078828650
}

\section{Online article number E4}

Refereed Paper - accepted 13 March 2013

DOI: 10.1038/sj.bdj.2013.687

${ }^{\circledR}$ British Dental Journal 2013; 215: E4 adversely affecting the economy by work loss and through the provision of high cost dental care. ${ }^{7}$

Even though local and national health surveys in the UK have continually assessed the oral health of children aged 5 to 15 years, ${ }^{8,9}$ few studies have examined the oral health of younger children. ${ }^{10-13}$ There is also overwhelming evidence that dental caries is unequally distributed, disproportionately affecting children living in deprived areas and low social-economic families. ${ }^{14}$ The 2003 UK Children's Dental Health Survey found that $60 \%$ of fiveyear-old children from 'deprived' schools (based on free-school meal entitlement) had caries experience compared to only $40 \%$ of five-year-old children attending 'non-deprived' schools. ${ }^{8}$ A study of threeto four-year-old Scottish children showed that social inequalities in oral health occur within deprived areas. The caries prevalence among three- to four-year-old children living in the most deprived areas in Glasgow was 32\% compared to only $16 \%$ in the least deprived areas. ${ }^{11}$

As expected a significantly lower percentage of three- to four-year-old children living in Hackney (16\%) had caries experience compared to the percentage of children living in Tower Hamlets (24.9\%) and Newham (28.6\%) who had caries experience. ${ }^{12}$ The newly released Index of Multiple Deprivation (IMD) 2010 showed that Hackney, Tower Hamlets and Newham in Inner North East London are the three most deprived boroughs in England. ${ }^{15}$ Inner North East London has high unemployment rates, low levels of education levels and poor housing. ${ }^{16-18}$ In 2006 80\% of children in Tower Hamlets, $68 \%$ of children in Hackney and 69\% of children in Newham resided in low income families compared to only $48 \%$ of children in London overall. ${ }^{19}$

Remarkably the prevalence of caries among three- to four-year-old children living in Inner North East London $(23.5 \%)^{12}$ was lower than the prevalence of caries among five-year-old children attending schools in 'non-deprived' in the UK $(40 \%) .{ }^{8}$ Similarly, three- to fouryear-old children living in Inner North East London had fewer teeth with caries experience (mean $\mathrm{dmft}=0.92$ ) than threeand-a-half- and four-and-a-half-year-old 
children in the UK in $1992 / 1993^{13}$ (mean $\mathrm{dmft}=1.3$ ), and five-year-old children in the UK in 2003 (mean $\mathrm{dmft}=1.6) .{ }^{8}$ Even though one should be cautious about comparing the results from a study carried out in 2007 with national data collected in 1992-1993 and 2003, the last UK Children's Dental Health Survey in 2003 suggested that the oral health of children in the UK had reached a plateau. ${ }^{8}$ There were no statistically significant difference between the caries experience of five-year-old children in 1993 and 2003. ${ }^{8}$ Therefore, one can justifiably compare the findings for three- to four-year-old children in Inner North East London with the UK National Diet and Nutrition Survey of three-and-a-half- and four-and-a-halfyear-old children.

Inner North East London has also historically attracted immigrants and remains one of the most ethnically, religiously and linguistically diverse regions in the UK. Four in ten residents in Inner North East London were born outside of the UK, emigrating from 47 different countries. ${ }^{16-18}$ Newham is home to the highest proportion (60\%) of Black and Minority Ethnic (BME) residents in the UK. ${ }^{17}$ Blacks and Asians are the most prevalent ethnic groups in Newham while Asians (Bangladeshis) and Blacks make up the main ethnic groups in Tower Hamlets and Hackney respectively. ${ }^{16-18}$ While some studies in the UK have shown high caries experience among preschool children from ethnic minority groups, ${ }^{20,21}$ other studies have found that oral health differences between Asian, White and Black children attenuated or disappeared after matching by social class. ${ }^{22,23}$

Despite the ethnic diversity in addition to the high concentration of deprivation in Inner North East London, we know little about ethnic disparities in oral health among preschool children living in Inner North East London. The purpose of this paper was to assess ethnic differences related to caries experience in three- to four-year-old nursery children living in Tower Hamlets, Hackney and Newham.

\section{METHODS}

\section{Study design}

This survey was conducted in three Inner North East London boroughs in 2007:
Hackney, Tower Hamlets and Newham. This cross-sectional survey followed the methodology described by the British Association for the Study of Community Dentistry (BASCD). ${ }^{24}$ This study fell under the remit of NHS Dental Epidemiology programme and therefore did not require ethical review by a NHS Research Ethics Committee. ${ }^{25,26}$

The study population consisted of threeto four-year-old children attending local authority-run nurseries in Inner North East London. British Association for the Study of Community Dentistry (BASCD) recommends a minimum sample size recommended of at least 250-300 subjects in each borough. ${ }^{27}$ In order to obtain the required minimum number $(\mathrm{n}=250)$, we identified at least 400 children in each borough. We oversampled assuming that we would obtain a low response rate. There was no substitution for selected children who could not be examined.

A clustered sampling approach was used to select children. Following the sampling framework described by BASCD, we selected three independent random samples of three to four-year-old children in Hackney, Tower Hamlets and Newham. ${ }^{27}$ The first stage unit was nurseries; all local authority-run nurseries in the three boroughs were included in the sampling frame. A list of nursery schools in each borough was obtained from local education authorities. Since the BASCD protocol suggests that a minimum of 15 (preferably 20) first stage units (for example, nurseries) is acceptable, we selected 20 nursery schools from each borough. All pupils in the sample who attended school on the selected day and whose parents gave their positive consent were examined.

\section{Data collection}

Before the start of data collection a dentist and a scribe participated in a formal training and calibration exercise designed to address the procedures and the criteria to be used to identify dental caries experience in preschool children. The team included a community dental officer highly experienced in the BASCD epidemiological survey data collection procedures and a scribe.

Demographic information including the child's name, date of birth, parents' ethnicity and home postcode were obtained from the school records. Children's home postcodes were used to generate areabased deprivation scores based on the 2004 Index of Multiple Deprivation. ${ }^{28}$ Higher IMD scores indicate higher levels of deprivation. IMD scores were subdivided into quintiles with the 'least deprived' and 'most deprived' quintiles representing the least or most deprived 20\% wards in England. ${ }^{28}$

Clinical data was collected through a clinical examination by a single dentist. The dental examiner adhered to the BASCD diagnostic criteria for dental caries and oral sepsis. ${ }^{29}$ Radiographs were not taken. Clinical data was recorded at the tooth level at the time of the examination on paper or directly on to a laptop computer.

\section{Data analysis}

The data was first entered in an Excel spreadsheet and then transferred into the Statistical Package for Social Sciences (SPSS for Windows, version 15.0) ${ }^{30}$ to allow data cleaning of data entry errors and missing information. We weighted the data to ensure proportional representation of children from all three boroughs. This was necessary because children in Hackney and Tower Hamlets were underrepresented, while children in Newham were overrepresented. We re-categorised the 27 different ethnic groups to produce 13 groups: White British, White Eastern European, White Other, Black African, Black Other, Indian, Bangladeshi, Pakistani, Asian Other, Middle Eastern, Mixed, Other and unclassified. The 'White Other' category included White Other, White Irish, Greek/Turkish Cypriot, White European, Latin American, combined because of the small numbers. 'Black Other' included Black Other, Black Caribbean and Black British while the 'Asian Other' category included Asian Other, Sri Lankan, Filipino and Chinese.

All data analyses were carried out using STATA $11^{31}$ to account for the complex cluster sampling and to produce corrected standard errors and confidence intervals. ${ }^{32}$ The oral health outcomes were the mean number of teeth with caries experience (dmft), the mean number of teeth with untreated caries into dentine, the percentage of children with caries experience $(\mathrm{dmft}>0)$ and the percentage of children with one or more tooth with untreated 
Table 1 Mean number of teeth with caries experience (dmft) and the number ( $\%)$ of three- to four-year-old children with caries experience in 2007 by ethnic groups (weighted data, $n=1,297$ )

\begin{tabular}{|c|c|c|c|c|c|c|}
\hline Ethnic groups & $\begin{array}{l}\text { Mean number of teeth } \\
\text { with decay experience } \\
(\mathrm{dmft})(95 \% \mathrm{Cl})\end{array}$ & $\begin{array}{l}\text { Prevalence } \\
\text { rate ratios } \\
(95 \% \mathrm{Cl})\end{array}$ & $p$ value & $\begin{array}{l}\text { Number }(\%) \text { of } \\
\text { children with decay } \\
\text { experience }\end{array}$ & $\begin{array}{l}\text { Odds ratios } \\
(95 \% \mathrm{Cl})\end{array}$ & $p$ value \\
\hline White British & $0.60(0.29,0.92)$ & 1 & & $26(18.21)$ & 1 & \\
\hline White Eastern European & $2.56(1.12,3.99)$ & $4.22(1.87,9.56)$ & 0.001 & $15(50.74)$ & $4.62(1.63,13.13)$ & 0.005 \\
\hline White other & $1.09(0.22,2.41)$ & $1.81(0.47,6.98)$ & 0.38 & $8(21.69)$ & $1.24(0.36,4.35)$ & 0.73 \\
\hline Black African & $0.56(0.26,0.87)$ & $0.93(0.47,1.83)$ & 0.85 & $30(14.31)$ & $0.75(0.39,1.45)$ & 0.39 \\
\hline Black other & $0.35(0.53,1.15)$ & $0.58(0.21,1.56)$ & 0.28 & $10(10.73)$ & $0.54(0.16,1.86)$ & 0.32 \\
\hline Asian Indian & $0.84(0.95,1.56)$ & $1.39(0.73,2.64))$ & 0.30 & 26 (25.99) & $1.58(0.68,3.66)$ & 0.28 \\
\hline Asian Bangladeshi & $1.25(0.94,1.83)$ & $2.08(1.17,3.66)$ & 0.01 & $122(30.31)$ & $1.95(0.96,3.96)$ & 0.06 \\
\hline Asian Pakistani & $1.39(0.24,1.07)$ & $2.29(1.32,3.98)$ & 0.004 & 35 (31.70) & $2.08(1.03,3.28)$ & 0.04 \\
\hline Asian other & $0.66(0.04,1.10)$ & $1.08(0.46,2.51)$ & 0.85 & $19(24.05)$ & $1.42(0.62,3.28)$ & 0.40 \\
\hline Middle Eastern & $1.30(0.34,2.24)$ & $2.13(0.87,5.23)$ & 0.09 & $8(24.97)$ & $1.50(0.54,4.14)$ & 0.43 \\
\hline Mixed & $0.57(0.10,0.91)$ & $0.95(0.35,2.59)$ & 0.69 & $10(21.54)$ & $1.23(0.47,3.21)$ & 0.66 \\
\hline Other & $1.52(0.34,2.70)$ & $2.52(0.91,5.68)$ & 0.32 & $8(42.57)$ & $3.33(0.94,1.61)$ & 0.06 \\
\hline Unclassified & $0.20(0.03,0.37)$ & $0.33(0.11,5.68)$ & 0.36 & $8(11.88)$ & $0.61(0.23,1.61)$ & 0.31 \\
\hline Inner East London & $0.92(0.80,1.04)$ & & & 325 (23.54) & & \\
\hline
\end{tabular}

caries into dentine. Poisson regression tested associations between the oral health outcomes and explanatory variables (that is, gender, borough and ethnic group) producing prevalence rate ratios (PRR). Logistic tested associations between explanatory variables and children with caries experience and with caries into dentine producing odds ratios (OR). The level of significant for all tests was $\mathrm{p}<0.05$.

\section{RESULTS}

All 60 nurseries agreed to participate in the study. One thousand, two hundred and eighty-five three- to four-year-old children were successfully examined out of 2,434 who were originally sampled (response rate $=52.8 \%$ ). There were no significant differences between the response rates in Tower Hamlets (55.2\%), Hackney (51.8\%) and Newham (52.1\%). The sample included 243 three- to four-year-old children from Hackney, 333 children from Tower Hamlets and 709 children from Newham. The weighted samples of 372 children (29\%) from Hackney, 415 children (32\%) from Tower Hamlets and 510 (39\%) children from Newham reflected the population ratios of three- to four-yearold children in the three Inner North East London boroughs.
The mean age of children was 3.98 years (95\% CI: 3.93, 4.03) and $49.8 \%$ of the sample were boys. Children's parents came from 13 different ethnic backgrounds: White British (10.94\%), White Eastern European (1.94\%), White Other (2.74\%), Black African (15.6\%), Black Other (7.30\%), Indian (7.00\%), Bangladeshi (30.11\%), Pakistani (6.36\%), Asian Other (5.14\%), Middle Eastern (4.04\%), Mixed (2.86\%), Other (1.40\%) and unclassified (4.63\%). Almost all (99\%) children in the sample lived in the two most deprived quintiles in England. The mean IMD scores for children living in Tower Hamlets (51.11), Hackney (46.28) and Newham (43.77) were comparable, indicating similar levels of deprivation. The mean IMD scores in the sample were also comparable to the borough summaries produced by the Office of National Statistics. ${ }^{28}$

There were statistically significant differences related to caries experience among the 13 different ethnic groups (Table 1). Children whose parents were White European (mean $\mathrm{dmft}=2.56$ ), Bangladeshi (mean dmft $=1.25$ ) and Pakistani (mean $\mathrm{dmft}=1.39$ ) had significantly higher dmft scores than children who had White British parents (mean $\mathrm{dmft}=0.60)$ (Table 1). Moreover, while only $18.21 \%$ of children with White British parents had caries experience, $50.74 \%$ of children with White Eastern European parents and 31.70\% in children with Bangladeshi parents had caries experience (Table 1). White Eastern European children were therefore 4.62 times more likely to have caries experience than White British children (Table 1). Bangladeshi children were 2.08 times more likely to have caries experience than White British children (Table 1).

The number of untreated carious teeth was the major contributor to the $\mathrm{dmft}$ score; few children had filled teeth $(2.1 \%)$ or teeth extracted because of caries (1.7\%). Therefore, the findings related to untreated dental caries were similar to the caries experience findings. Importantly, a statistically significantly higher percentage of White Eastern European (43.95\%) children had one or more untreated carious primary tooth into dentine compared to White British children (17.4\%) (Table 2). White Eastern European children were therefore 3.71 times more likely to have one or more carious primary tooth than White British children (Table 2). Children whose parents were White European (mean dt $=1.91$ ), Asian Bangladeshi (mean dt $=1.05$ ) and Asian Pakistani $($ mean $\mathrm{dt}=1.11)$ had a 


\begin{tabular}{|c|c|c|c|c|c|c|}
\hline Ethnic groups & $\begin{array}{l}\text { Mean number of teeth with } \\
\text { caries into dentine }(95 \% \mathrm{Cl})\end{array}$ & $\begin{array}{l}\text { Prevalence } \\
\text { rate ratios } \\
(95 \% \mathrm{Cl})\end{array}$ & $p$ value & $\begin{array}{l}\text { Number (\%) of children } \\
\text { one or more tooth with } \\
\text { caries into dentine }\end{array}$ & $\begin{array}{l}\text { Odds ratios } \\
\text { (95\% C.I.) }\end{array}$ & $p$ value \\
\hline White British & $0.56(0.25,0.87)$ & 1 & & $25(17.42)$ & 1 & \\
\hline White Eastern European & $1.91(0.75,3.09)$ & $3.40(1.44,8.03)$ & 0.006 & $14(43.95)$ & $3.71(1.32,10.45)$ & 0.01 \\
\hline White Other & $1.09(0.23,2.41)$ & $1.94(0.50,7.59)$ & 0.33 & $8(21.69)$ & $1.31(0.37,4.66)$ & 0.67 \\
\hline Black African & $0.54(0.23,0.84)$ & $0.95(0.47,1.95)$ & 0.89 & 29 (13.95) & $0.77(0.38,1.53)$ & 0.45 \\
\hline Black other & $0.29(0.08,0.49)$ & $0.52(0.19,1.40)$ & 0.19 & $9(9.97)$ & $0.52(0.15,1.89)$ & 0.32 \\
\hline Asian Indian & $0.82(0.53,1.12)$ & $1.46(0.75,2.84)$ & 0.28 & $26(25.99)$ & $1.66(0.69,4.00)$ & 0.25 \\
\hline Asian Bangladeshi & $1.05(0.80,1.29)$ & $1.86(1.094,3.32)$ & 0.04 & $116(28.54)$ & $1.89(0.91,3.92)$ & 0.09 \\
\hline Asian Pakistani & $1.11(0.83,1.40)$ & $1.98(1.09,3.57)$ & 0.03 & $34(29.63)$ & $1.99(0.95,4.18)$ & 0.07 \\
\hline Asian other & $0.59(0.20,0.99)$ & $1.04(0.44,2.49)$ & 0.91 & $17(21.90)$ & $1.32(0.56,3.16)$ & 0.52 \\
\hline Middle Eastern & $1.19(0.22,2.17)$ & $2.12(0.81,5.53)$ & 0.12 & $8(24.97)$ & $1.58(0.55,4.54$ & 0.39 \\
\hline Mixed & $0.57(0.04,1.10)$ & $1.02(0.37,2.78)$ & 0.97 & $10(21.54)$ & $1.30(0.50,3.39)$ & 0.59 \\
\hline Other & $1.44(0.30,0.31)$ & $2.56(0.09,1.86)$ & 0.30 & 7 (38.61) & $2.98(0.86,10.30)$ & 0.08 \\
\hline Unclassified & $0.16(0.08,1.40)$ & $0.29(0.12,1.16)$ & 0.36 & $6(9.49)$ & $0.50(0.18,1.39)$ & 0.18 \\
\hline Inner North East London & $0.80(0.64,0.96)$ & & & $309(22.27)$ & & \\
\hline
\end{tabular}

significantly higher number of untreated carious teeth than children who had White British parents (mean $d t=0.56$ ) (Table 2).

\section{DISCUSSION}

Despite worldwide ethnic diversity, most studies on ethnic disparities compare Whites with Blacks and Asians, failing to demonstrate disparities within Whites, Blacks and Asians. To our knowledge, this is the first UK study to report higher caries experience among White Eastern European preschool children compared with children from other ethnic groups in the UK. One explanation for this disparity is income deprivation. Approximately 13\% of recent immigrants to the UK in 2010 came from one of the eight A8 East European countries (the Czech Republic, Cyprus, Estonia, Hungary, Latvia, Lithuania, Malta, Poland, Slovakia and Slovenia). ${ }^{33}$ Labour force statistics also show that Eastern European immigrants are more likely to be employed in low pay-low skill jobs than UK-born workers. ${ }^{34}$

While studies in the UK have shown high caries experience among preschool children from Asian backgrounds, ${ }^{35}$ this study showed a statistically significant difference within the Asian ethnic group. While preschool children Asian Bangladeshi and Asian Pakistani children had significantly higher level of caries than White children, Asian Indian children had lower (albeit not statistically significant) levels of caries experience than White children $(p=0.30)$. Moreover, Asian Pakistani children had statistically significant higher caries experience than Asian Indian children $(p=0.003)$. Explanations for ethnic oral health disparities in addition to income deprivation may include infant feeding habits, ${ }^{36}$ language barriers, ${ }^{37}$ cultural beliefs about oral health ${ }^{38}$ and dentists perceptions about treating ethnic minority children. ${ }^{39}$

This study showed that White and Black children living in Inner East London have similar dental health. Black children had lower caries experience than White British children, but this difference was not statistically significant $(p=0.27)$. Similarly, this study identified a small non-statistically significant difference between Black Africans and other Blacks including Black Caribbean $(p=0.28)$. The low level of caries among Black children reported in this study is in agreement with studies from African countries. Caries experience among children is lower in most African countries than in the UK. ${ }^{40}$. Other studies have also found low caries experience among Afro-Caribbean children in the UK. ${ }^{41}$
The findings from this study have implications for commissioning local oral health services to address not only the clear ethnic oral health inequalities but also the level of untreated caries among preschool children. Given that there were approximately 21,950 three- to four-year-old children attending nurseries in Inner North East London in 2010, ${ }^{42}$ this represents an estimated 4,888 preschool children in Inner North East London with one or more untreated carious primary tooth and an estimated 17,560 primary teeth requiring restorations. This illustrates the potential cost savings of preventing dental caries in preschool children by applying cultural sensitive programmes in addition to following general evidence based preventive approaches recommended in the Department of Health's Delivering better oral health: an evidence-based toolkit for prevention. ${ }^{43}$

This study underscored the need for oral health promotion initiatives to address cultural issues when targeting preschool children in deprived areas. Early year intervention programmes such as the national Sure Start programme have been operating since 1999 and these schemes have been increasingly criticised for not addressing the needs of ethnic minorities. ${ }^{44}$ Future research should identify the 
barriers and facilitators of oral health among White European, Pakistanis, and Bangladeshi children living in deprived areas in order to develop effective oral health programmes. Also, why ethnic minorities such as Indians and Blacks had such good oral health despite living in a highly deprived area must be answered.

The strengths of this study examining ethnic disparities in caries experience and treatment need includes the use of methodologically sound epidemiological data to assess the oral health of preschool children attending nurseries in Inner North East London. The sample size was sufficiently large enough to achieve good statistical power to report children's oral health status and treatment needs. However, we acknowledge the study limitation consistent with all cross-sectional studies that preclude us from inferring causality between ethnicity and oral health. Moreover, one should also interpret the finding of this study with caution because we studied 13 different ethnic group and some ethnic categories included few children. This increases the likelihood of a type II error where because of insufficient power we falsely conclude that there are no ethnic differences when real differences exist. ${ }^{45}$ This may explain the observed lack of statistical difference between the percentage of Black and White British children who had caries experience and untreated carious teeth. Further research requires a larger sample including a sufficient number of children from each ethnic group.

In conclusion, this study identified significant ethnic oral health disparities within a highly deprived inner city area. Preschool children from a White Eastern European, Pakistani and Bangladeshi background had significantly higher caries experience than children who had White British parents. Interestingly, children from a Black, Asian Indian and White British background experienced comparable levels of caries. A similar pattern was observed for untreated decay. These findings have profound implications for commissioning dental services and oral health promotion.

1. Filstrup $S$ L, Briskie D, da Fonseca M, Lawrence $L_{\text {, }}$ Wandera A, Inglehart M R. Early childhood caries and quality of life: child and parent perspectives. Pediatr Dent 2003; 25: 431-440.

2. Low W, Tan S, Schwartz S. The effect of severe caries on the quality of life in young children. Pediatr
Dent 1999; 21: 325-326.

3. Quiñonez C, Gibson D, Jokovic A, Locker D. Day surgery visits for dental problems. Community Dent Oral Epidemio/ 2009; 37: 562-567.

4. Sheiham A. Dental caries affects body weight, growth and quality of life in preschool children. Br Dent J 2006; 201: 625-626.

5. Ratnayake N, Ekanayake L. Prevalence and impact of oral pain in 8-year-old children in Sri Lanka. Int J Paediatr Dent 2005: 15: 105-112.

6. Shepherd M A, Nadanovsky P, Sheiham A. The prevalence and impact of dental pain in 8-year-old school children in Harrow, England. Br Dent J 1999; 187: 38-41.

7. Gift $H$, Reisine $S$, Larach D. The social impact of dental problems and visits. Am J Public Health 1992; 82: 1663-1668.

8. Office for National Statistics. Children's dental health in the United Kingdom, 2003. London: OFNS, 2005.

9. Pitts N, Boyles J, Nugent Z, Thomas N, Pine C. The dental caries experience of 5-year-old children in Great Britain (2005/6). Surveys coordinated by the British Association for the study of community dentistry. Community Dent Health 2007; 24: 59-63.

10. Holt R D. epidemiology: a survey of caries in three-year-olds in Greater Manchester. Br Dent J 2001; 190: 372-372.

11. McMahon A D, Blair Y, McCall D R, Macpherson L M. The dental health of three-year-old children in Greater Glasgow, Scotland. Br Dent J 2010; 209: E5-E5.

12. Marcenes W, Wright D, Murray S, Redshaw $P$, Bennett U. The oral health of three-four-yearold children in Inner North East London in 2007. London: The Institute of Dentistry, Barts and the London School of Medicine and Dentistry, Queen Mary University of London, Hackney PCT, Tower Hamlets PCT, Newham PCT, 2008. Online article available at http://www.dentistry.qmul.ac.uk/ images/downloads/OHNA/pdf/The\%200ral\%20 Health\%20of\%20Three-\%20Four-Year-0ld\%20 Children\%20in\%20Inner\%20North\%20East\%20 London\%20in\%202007.pdf (accessed May 2013).

13. Moynihan P J, Holt R D. The national diet and nutrition survey of 1.5 to 4.5 year old children: summary of the findings of the dental survey. Br Dent J 1996; 181: 328-332.

14. Locker D. Deprivation and oral health: a review. Community Dent Oral Epidemiol 2000; 28: 161-169.

15. Department for Communities and Local Government. The English indices of deprivation 2010. London: Department for Communities and Local Government, 2011.

16. NHS City and Hackney. The health and wellbeing profile for Hackney and the City. London: NHS City and Hackney, 2009.

17. NHS Newham. Joint Strategic Needs Assessment 2010. The London Borough of Newham. London: NHS Newham, 2011.

18. NHS Tower Hamlets. Health and wellbeing in Tower Hamlets. Tower Hamlets Joint Strategic Needs Assessment 2010-2011. London: NHS Tower Hamlets, 2011

19. Centre for Economic and Social Inclusion. Child Poverty Toolkit. Online Information available at http://www.cesi.org.uk/statistics/tools (accessed July 2013)

20. Anantharaman D, Marron M, Lagiou P et al. Population attributable risk of tobacco and alcohol for upper aerodigestive tract cancer. Oral Oncol 2011; 47: 725-731.

21. Gray M, Morris A J, Davies J. The oral health of South Asian five-year-old children in deprived areas of Dudley compared with White children of equal deprivation and fluoridation status. Community Dent Health 2000; 17: 243-245.

22. Watt $R$, Sheiham $A$. Inequalities in oral health: a review of the evidence and recommendations fo action. Br Dent J 1999; 187: 6-12.

23. Bedi R, Uppal R D. The oral health of minority ethnic communities in the United Kingdom. In Bed R, Bahl V, Rayan R R (eds) Dentists, patients and ethnic minorities. pp 23-33. London: Royal College of Surgeons of England, 1996.
24. British Association of Community Dentistry. NHS dental epidemiological oral health survey of 5-year-old children in England 2007/2008. London: BASCD: 2007.

25. Department of Health. National Health Service, England. The functions of primary care trusts (dental public health) (England) regulations 2006. London: DH, 2006.

26. Department Of Health. National Health Service Act 2006. Directions to primary care trust concerning the exercise of dental public health functions 2008. London: $\mathrm{DH}, 2006$.

27. Pine C M, Pitts N B, Nugent Z J. British Association for the Study of Community Dentistry (BASCD) guidance on sampling for surveys of child dental health. A BASCD coordinated dental epidemiology programme quality standard. Community Dent Health 1997: 14(Suppl 1): 10-17.

28. Office of the Deputy Prime Minister. The English indices of deprivation 2004 (revised). London: Queen's Printer and Controller of Her Majesty's Stationery Office, 2004.

29. Pitts N B, Evans D J, Pine C M. British Association for the Study of Community Dentistry (BASCD) diagnostic criteria for caries prevalence surveys-1996/97. Community Dent Health 1997; 14(Suppl 1): 6-9.

30. SPSS Inc. SPSS 15. GPL reference guide. Chicago: SPSS, 2005.

31. StataCorp. 2009. Stata Statistical Software: Release 11. College Station, TX: StataCorp LP.

32. Caplan D J, Slade G D, Gansky S A. Complex sampling: implications for data analysis. J Public Health Dent 1999; 59: 52-59.

33. Office for National Statistics. Net migration rises for 242,000. News release. London: OFNS, 2011.

34. Office for National Statistics. Non-UK born workers - 2011. London: OFNS, 2011.

35. Godson J H, Williams S A. Oral health and health related behaviours among three-year-old children born to first and second generation Pakistani mothers in Bradford UK. Community Dent Health 1996; 13: 27-33.

36. Watt R G. A national survey of infant feeding in Asian families: summary of findings relevant to ora health. Br Dent J 2000; 188: 16-20.

37. Bedi R. Ethnic indicators of dental health for young Asian schoolchildren resident in areas of multiple deprivation. Br Dent J 1989; 166: 331-334.

38. Adair P M, Pine C M, Burnside $G$ et al. Familial and cultural perceptions and beliefs of oral hygiene and dietary practices among ethnically and socio-economically diverse groups. Community Dent Health 2004; 21(1 Suppl): 102-111.

39. Williams S A, Godson J H, Ahmed I A. Dentists' perceptions of difficulties encountered in providing dental care for British Asians. Community Dent Health 1995; 12: 30-34.

40. World Health Organization. The World oral health report 2003. Continuous improvement of oral health in the 21st century - the approach of the WHO Global Oral Health Programme. Geneva: WHO, 2003.

41. Zoitopoulos L, Brailsford S R, Gelbier S, Ludford R W, Marchant S H, Beighton D. Dental caries and caries-associated microorganisms in the saliva and plaque of 3-and 4-year-old Afro-caribbean and Caucasian children in South London. Arch Oral Biol 1996: 41: 1011-1018.

42. Department for Education. Provision for children under 5 years of age in England: January 2010. Online information available at https://www.gov.uk/ government/publications/provision-for-childrenunder-5-years-of-age-in-england-january-2010 (accessed July 2013)

43. Department of Health, British Association for the Study of Community Dentistry. Delivering better oral health: an evidence-based toolkit for prevention. 2nd ed. London, DH: 2009.

44. Craig G. Sure start and black and minority ehnic populations: national evaluation report. London: SureStart, 2007.

45. Petrie A, Bulman J S, Osborn J F. Further statistics in dentistry part 4: clinical trials 2. Br Dent J 2002: 193: 557-561. 